\title{
ASPECTOS RELIGIOSOS DE LA COLONIZACIÓN FENICO-PÚNICA EN LA PENÍNSULA IBÉRICA: LAS ESTELAS DE VILLARICOS (ALMERÍA)
}

\author{
RELIGIOUS ASPECTS OF THE PHOENICIAN AND PUNIC COLONISATION \\ OF IBERIA. THE VILLARICOS (ALMERÍA) STELAE
}

\author{
por \\ MARÍA BELÉN 1
}

RESUMEN Se estudian en estas páginas las estelas que Siret encontró en la necrópolis de Villaricos y que se conservan en el Museo Arqueológico Nacional. Se analizan los diferentes tipos y se recoge toda la información disponible acerca de las características de las tumbas en que se hallaron. Las ilustraciones reproducen los originales de Pedro Flores.

\begin{abstract}
In these pages, we study the stelae wich were found by Siret in the necropolis of Villaricos. These stelae are kept in the National Archaeological Museum. The differents types are analized. We compile also all the information about the characteristics of the graves in wich those are found. The illustrations reproduce the original drawings of $\mathrm{P}$. Flores.
\end{abstract}

\section{INTRODUCCIÓN ${ }^{2}$}

El conocimiento de la religión de los colonizadores orientales en la Península Ibérica es todavía muy pobre. Esta situación resulta llamativa teniendo en cuenta que la arqueología fenicio-púnica ha alcanzado en los últimos 30 años un desarrollo notable. En la actualidad conocemos numerosos poblados (Schubart, 1982:7199; Aubet, 1987:228-278), algunos realmente espléndidos, como el que se excava en el lugar conocido como Castillo de Doña Blanca, en las proximidades de la bahía de Cádiz (Ruiz Mata,1988:36-48). Pero por extraño que pueda parecer, ni siquiera poseemos información suficiente sobre las costumbres funerarias de los colo-

1. Departamento de Prehistoria y Arqueología (Facultad de Geografía e Historia de Sevilla).

2. Este trabajo se realizó en el marco del Proyecto de Investigación FUNUS, subvencionado por la Consejería de Educación de la Junta de Andalucía, y fue presentado en The First International Conference in America on Iberian Archaeology: New Perspectives in Western Mediterranean Archaeology: Encounters, Transitions, Transformations, Tufts University, Oct. 4-6,1991. La consulta de documentación que entonces no pudimos realizar, nos ha permitido añadir y corregir algunos datos al texto original, que será publicado en inglés. 
nos más antiguos, o bien no se han analizado adecuadamente los datos disponibles, de lo contrario no podrían entenderse las vacilaciones que se siguen produciendo a la hora de interpretar algunos cementerios que no responden a los que la investigación ha venido considerando modelos normativos de las prácticas funerarias de las comunidades fenicias y púnicas.

Con todo, mucho más incompleta es la documentación acerca de otros aspectos de la religiosidad como lugares de culto, divinidades, etc. Los escasos trabajos de síntesis que se han hecho sobre estas cuestiones, más que instruir confunden al lector, porque en ellos no se encuentra una distinción clara entre lo que razonablemente cabe interpretar como elementos de religiosidad de las poblaciones orientales en la península Ibérica, y aquello otro que, por el contrario, podría tomarse como prueba de la adopción de creencias foráneas por parte de las comunidades locales (cf. Blázquez, 1983: 36-66).

Uno de los asuntos pendientes de solución en este campo es la ausencia de tofets en las ciudades feniciopúnicas de occidente. En opinión de algunos investigadores, el hecho no es fortuito y se justificaría por el hecho de que los colonos que llegan hasta estas tierras proceden de territorios del Próximo Oriente en los que tampoco abundan las manifestaciones del rito molk (Aubet,1987:278). Hasta el momento, sólo Cádiz ha proporcionado alguna documentación acerca de la existencia de sacrificios infantiles en el ámbito púnico peninsular (Corzo,1989) pero tiene el inconveniente de ser muy tardía (segunda mitad del siglo I a.C) y de que no todos los arqueólogos que trabajan en la ciudad comparten la misma interpretación. En excavaciones practicadas en 1980 en el área de la necrópolis gaditana, se encontraron seis enterramientos de niños con los cráneos, al parecer, inequívocamente fracturados de forma violenta. El hallazgo se ha considerado como la prueba de que se practicaban por la población púnica ciertas costumbres bárbaras que fueron abolidas por César hacia el año 61, según refiere Cicerón (Pro Balb.43). Sin entrar en la discusión de si la interpretación está o no fundamentada, queda claro, en cualquier caso, que los niños recibieron sepultura en el mismo cementerio que los adultos y otros niños muertos en muy distintas circunstancias (Corzo y Ferreiro, 1987: 57-61). También en la necrópolis de Ibiza, los niños reposan junto a sus mayores (Gómez Bellard, 1990:163) y no en recintos aparte.

El panorama, pues, no es demasiado brillante. Resulta evidente que los documentos que se refieren a las creencias religiosas de las comunidades orientales de la Península Ibérica necesitan una revisión que comprenda, por un lado un análisis serio de los datos ya conocidos y, por otro, la divulgación de muchos materiales todavía inéditos procedentes de excavaciones antiguas. En esta línea más modesta se inserta este trabajo.

Hace algunos años, el Prof.M.Fernández-Miranda nos propuso el estudio de las estelas halladas en las necrópolis púnicas del sur de España; en su opinión, la revisión de estos materiales serviría para aclarar la función de las distintas piezas en los yacimientos de procedencia y zanjar, entre otras, la cuestión de su posible adscripción a los tofets. Ante la imposibilidad de abordar aquí el estudio completo de estos monumentos en piedra ${ }^{3}$, hemos seleccionado un conjunto recuperado en las excavaciones dirigidas por L. Siret en la necrópolis púnica de Villaricos (Almería) ${ }^{4}$.

\section{VILLARICOS: EL ASENTAMIENTO Y LA NECRÓPOLIS PÚNICA}

El poblado de Villaricos que desde finales del siglo pasado se viene identificando con la antigua Baria,

3. En otro lugar hemos publicado las estelas de Cádiz: Belén, 1992-93.

4. Algunos datos técnicos y las fotos que ilustran este trabajo nos fueron facilitados por el Profesor M. FernándezMiranda. Agradezco a la Dra. A. Rodero, Conservadora del Museo Arqueológico Nacional y a D. Antonio Madrigal, la cordialidad y diligencia con que han atendido mis numerosas consultas, y a M.Sánchez Andréu la reproducción de los dibujos que aquí se insertan. 
ocupa un lugar de cierta elevación sobre la desembocadura del río Almanzora, frente al Mediterráneo (Fig.1). Se aceptaba hasta ahora que su fundación se había producido en algún momento de la primera mitad del siglo VI a.C., pero hallazgos recientes sugieren que el primer asentamiento pudo ser coetáneo de las más antiguas colonias del litoral de Málaga. Otros yacimientos situados más al interior, sobre pequeñas colinas que quedaban al borde de la antigua línea de costa, han proporcionado también cerámicas fenicias fechadas en el siglo VIII a.C. (Carrilero y otros, 1993:104).

Parece que la principal actividad económica de esta población fue la explotación de los variados recursos minerales de la zona, junto con la pesca y las industrias derivadas de la misma.

Villaricos pudo albergar una comunidad de, aproximadamente, unas 1200 personas, integrada por extranjeros y gentes de sustrato autóctono (González Wagner, 1983: 470). Unos y otros se enterraron en un cementerio situado al oeste de la ciudad.

Las primeras excavaciones en la necrópolis se llevaron a cabo a fines del siglo pasado bajo la dirección de Luis Siret ,que en 1906 ofreció algunos resultados en una obra de contenido más amplio. En su estudio ordenó las sepulturas en seis grupos diferentes atendiendo a los objetos más representativos encontrados en ellas (Siret,1906: 392 (16)). Los trabajos prosiguieron todavía durante unos años y a fines de los 40, M. Astruc (1951) publicó una obra monográfica basada en el estudio de las notas de campo y de los materiales de las casi 2000 tumbas que se llegaron a recuperar. En ésta se clasifican los enterramientos en 10 grupos de acuerdo con "el rito sepulcral y la forma de las tumbas" (Astruc, 1951:14). De ellos, 3 grupos corresponden a enterramientos de incineración (A,E,I), 5 a los de inhumación (B,C,F,G,H) y 2 agrupan las tumbas en que se dan conjuntamente incineraciones e inhumaciones (D,J). Esta ordenación, sin embargo, resulta en general muy poco clara.

A partir de 1975 y hasta 1978, la Dra. Mª J. Almagro Gorbea prosiguió las investigaciones arqueológicas, publicando los resultados unos años después (M J J. Almagro Gorbea, 1984).

La necrópolis de Villaricos presenta una amplia tipología de enterramientos. La mayor variedad se registra entre las sepulturas de inhumación, pero los tipos esenciales se reducen a tres: Fosas simples de forma rectangular, excavadas en el terreno; fosas rectangulares que se abren al fondo de un pozo ancho y profundo y cámaras hipogeas con pozo o dromos de acceso, excavadas en el terreno o construidas con sillares. En los tres casos, con mucha frecuencia, los cadáveres yacían en ataúdes de madera. Algunas inhumaciones infantiles se cubrieron con ánforas.

Por su parte, las tumbas de cremación son más sencillas; consisten en simples hoyos en cuyo interior se recogieron los restos dentro de un recipiente cerámico, o sobre el propio suelo. Algunas cremaciones se depositaron sobre las lajas de cobertura de tumbas de inhumación, como sucedió en la n⿳0 7185 (Fig.5:1), o aprovecharon las antiguas cámaras hipogeas ya en desuso (Ma J. Almagro Gorbea, 1984:629 y 631).

\section{LAS ESTELAS 6 DE LA NECRÓPOLIS DE VILLARICOS.}

Muchas de las piezas que recogemos se conocían ya a través de las publicaciones mencionadas de Siret (1906:463 (87),lám.XX) y de Astruc (1951:láms.L-LII). Sin embargo, los datos que proporcionan ambos

5. Según las notas de Flores: Cuaderno 711-749, hoja 8 vuelto. Todas las citas que utilizaremos aquí, se refieren a la transcripción de los cuadernos de excavación de P. Flores que posee el Museo Arqueológico Nacional.

6. Puesto que no hemos encontrado en la bibliografía especializada unanimidad al utilizar los términos cipo y estela, empleamos este último con el sentido que recoge el Diccionario de la Real Academia Española: "Monumento conmemorativo que se erige sobre el suelo en forma de lápida, pedestal o cipo". 
autores son tan vagos e imprecisos, que no resulta posible saber en qué circunstancia o en relación con qué sepultura se habían hallado. Astruc suele indicar ${ }^{7}$ las tumbas que tenían estelas, pero no especifica de qué pieza se trata en cada caso. La consulta de los cuadernos de Pedro Flores, capataz de Siret y excavador de la mayor parte de la necrópolis, y de los inventarios y dibujos de Siret depositados en el Museo Arqueológico Nacional ${ }^{8}$, nos ha permitido algunas precisiones en ese sentido. Con los datos entresacados de las diversas fuentes de información, hemos elaborado la relación de tumbas con estelas que se recoge en el cuadro 1 y la clasificación que muestra el Cuadro 2.

\begin{tabular}{|c|c|c|c|c|c|c|c|c|c|c|}
\hline GRUPOS & A & B & $\mathrm{C}$ & $\mathrm{D}$ & $\mathrm{E}$ & $\mathrm{F}$ & $\mathrm{G}$ & $\mathrm{H}$ & I & $\mathbf{J}$ \\
\hline TUMBAS & 583 & & $\begin{array}{r}26 \\
460 \\
462 \\
511 \\
513 \\
515 \\
521 \\
591 \\
601 \\
674 \\
841 \\
882 \\
997 \\
1.008 \\
1.024 \\
1.626\end{array}$ & 718 & 309 & $\begin{array}{l}321 \\
530 \\
572 \\
710\end{array}$ & 612 & & $\begin{array}{l}358 \\
717\end{array}$ & $\begin{array}{r}411 / 2 \\
413 / 2 \\
556 \\
560 \\
677 / 4 \\
693 / 8 \\
986 / 4\end{array}$ \\
\hline
\end{tabular}

Cuadro 1. Ritual y estructura de las tumbas con estelas, según la clasificación de Astruc, 19519 .

1. Las estelas más sencillas consisten en piedras alargadas, de base rectangular, acabadas en punta. Debieron ser las más abundantes pero quizá muchas de ellas pasaron desapercibidas para los excavadores. En los almacenes del M.A.N. se conserva una pieza que mide 57 centímetros de longitud ${ }^{10}$, pero se hallaron otras mayores ${ }^{11}$, y M $\mathrm{M}^{\mathrm{a}}$ J. Almagro (1984: 85 y 117 y láms. III y V:12) encontró varias "de gran tamaño" durante las campañas de excavación que realizó en la necrópolis de incineración de los siglos III-II a.C. Con frecuencia las piedras iban revestidas de una capa de yeso de distinta consistencia ${ }^{12}$.

7. Cf. nota 9.

8. En adelante utilizaremos la abreviatura M.A.N.

9. En la descripción del grupo $\mathrm{C}$, la autora no especifica en qué tumbas se hallaron estelas. La relación que ofrecemos se basa en las notas de Flores y en las piezas dibujadas por Siret sobre las cuales figura el número de la tumba.

10. № de inventario, 1935/4 Vill./18.

11. En la tumba 530, Flores describe una piedra con extremo apuntado, de $85 \mathrm{cms}$. de largo (Cuaderno 522-545, hoja 20 vuelto, 21 recto); y la de la Tumba 882 tenía 1,28 metros (Cuaderno 875-912, hoja 8 vuelto, hoja 9 recto). También las había más pequeñas: la de la Tumba 997 que se conserva en el M.A.N. tenía poco más de $33 \mathrm{cms}$.

12. A veces esta capa es tan sólida que se ha conservado, como si fuera un molde, separada de la piedra que le sirvió de soporte: T. 26: Cuaderno 1-45, y T. 997: almacenes del M.A.N. 
En este grupo hay que incluir la única pieza con inscripción funeraria localizada en la necrópolis. Apareció sin contexto entre las sepulturas de incineración (Siret, 1906: 403 (27) y lám. XX,2); Astruc, 1951: 56 y lám.LI) ${ }^{13}$. Mide $97 \mathrm{cms}$. de altura y lleva grabado un epitafio en 4 renglones que ha sído leído como "Sepulcro de/ Ger'as/toret hijo de/Ba'alpilles" (Sola Solé, 1955: 47) (Lám. I). El nombre del difunto es un teóforo que se repite en varias inscripciones funerarias de Cartago (Bénichou-Safar, 1982: №s. 7,18 y 33, pp. 208, 211 y 213, respectivamente). Existe unanimidad de criterio al fechar esta estela a fines del siglo $\mathrm{V}$ o principios del IV a.C. (Fuentes Estañol, 1986:9; Guzzo Amadasi, 1978:35; Solá Solé, 1955:47). No abundan los epitafios en las necrópolis fenicio-púnicas del occidente mediterráneo, pero están atestiguados desde el siglo VII a.C.: en una tumba de la necrópolis Laurita (Almuñécar, Granada), se indicó con pintura sobre una urna de alabastro el nombre del difunto (Fuentes Estañol,1986: 16, nº 06.01).

Otras estelas igualmente sencillas presentan el extremo superior redondeado. En el M.A.N hemos podido examinar una pieza de estas características, de unos $94 \mathrm{cms}$. de largo ${ }^{14}$, y Flores encontró otra en la tumba de incineración n² 309, "arreglada como de haber sido un San Antonio" (Fig.2:4). Esta última podría ser una de las piezas que dibujó Siret (Fig.2:5), aunque no poseemos otros elementos de juicio que nos permitan estar seguros. La estela de la sepultura 710 (Fig.2:3) podría terminar en forma redondeada, aunque no excluímos que pueda tratarse de un ejemplar troncopiramidal con extremo desgastado ${ }^{15}$.

En ocasiones se usaron también como estelas bloques de piedra someramente desbastados, como el ejemplar de la Tumba 841 (Fig.2:1 y 2), o como el que se encontró en la tumba 102416, seguramente no muy diferentes de los que indicaban las sepulturas en la necrópolis de Olbia durante los siglos III-II a.C. (Levi, 1950: 13 y 36), o de las "piedras empinadas" que Flores menciona en las tumbas 556 y $583^{17}$ y que M J.Almagro (1984:58 y 85) encontró en el hipogeo H-5. Piezas de las mismas características se documentaron también en la Necrópolis de Dermech, en Cartago (Gauckler, 1915,I:13).

2. Las estelas en forma de pirámide son las más frecuentes en el yacimiento (Siret, 1906: 408). Tienen base cuadrada o rectangular y se labraron en arenisca o en caliza muy blanda; muchas recibieron un enlucido de yeso que les daría un aspecto de menor tosquedad. Ninguno de los ocho ejemplares que se conservan en el M.A.N. está completo, por lo cual resulta difícil hacerse idea de qué tamaño pudieron tener, pero sí parece evidente que había una cierta variabilidad a este respecto, pues mientras unas piezas sobrepasan los 50 centímetros de altura, otras no llegaban a los $20^{18}$ (Láms. II-IV).

De acuerdo con los datos que hemos podido recabar, parece seguro el hallazgo de estelas piramidales en

13. Siret, 1906: 403 (27), indica que la estela se halló entre las sepulturas del grupo III y en la pág. 408 (32) añade: "Cerca de las urnas estaban los monumentos de arte oriental: la diosa sentada y la esfinge; y sobre todo, el único nombre que conocemos de los ahí sepultados, es el de un hijo de Cartago, escrito en lengua púnica".

14. № inventario 1935/4. Vill./24.

15. De hecho, Astruc, 1951:50, indica que tres estelas que se hallaron en sendas fosas del grupo $\mathrm{F}$, al cual pertenece esta sepultura, tenían forma piramidal: cf. nota 23.

16. En esta sepultura se hallaron además del altar que se menciona más adelante, otras dos piedras con restos de yeso blanco; a juzgar por el croquis de P. Flores, una tenía forma ligeramente troncocónica y la otra parece un simple bloque alargado: Cuaderno $987-1024$, hoja 39 vuelto y 40 recto.

17. Cuaderno 546-586, hojas 10 vuelto a 13 vuelto, y 34 vuelto, respectivamente. En la tumba 556 se encontró, además, una estela piramidal, cf. nota 21.

18. La más pequeña de las estelas de este tipo se halló en la T. 556: $9 \mathrm{cms}$. de altura, por 11 de ancho y 12 de espesor. Se conserva en el M.A.N. con el $n^{\circ}$ de inventario 1935/4.Vill./ T.556/ 210. 
las sepulturas $321,358,462,513,515,556,591,601,612$ y $717^{19}$, y probable en la $413 / 2^{20}, 460^{21}, 511^{22}$, $560,572,677 / 4,693 / 8,710$ y $1024^{23}$ (figura 3 ).

\begin{tabular}{lrrrr}
\hline GRUPO & \multicolumn{1}{c}{1} & \multicolumn{1}{c}{2} & \multicolumn{1}{c}{3} & \multicolumn{1}{c}{$?$} \\
\hline TUMBAS & 26 & 321 & $411 / 2$ & $411 / 2$ \\
& 309 & 358 & 718 & 674 \\
& 530 & $413 / 2$ & $986 / 4$ & 1.008 \\
& 556 & 460 & 1.024 & \\
& 560 & 462 & 1.626 & \\
& 583 & 511 & & \\
& 841 & 513 & & \\
& 882 & 515 & & \\
& 997 & 521 & & \\
& 1.024 & 556 & & \\
& & 560 & & \\
& & 572 & & \\
& & 591 & & \\
& & 601 & & \\
& & 612 & & \\
& & $693 / 4$ & & \\
& & 710 & & \\
& & 717 & & \\
& & 1.024 & & \\
\hline
\end{tabular}

Cuadro 2. Clasificación de las estelas de Villaricos.

19. La estela de la T. 556 es la única que está identificada : cf. nota 18. Astruc, 1951: 56, nota 368, cita expresamente el hallazgo de estelas piramidales en las tumbas 358 y 717 . La estela de la sepultura 591 está representada en los inventarios de modo que no queda duda de su pertenencia a este grupo; respecto a las restantes, el número de la tumba aparece sobre dibujos y croquis donde se representan las piezas. Los dibujos y referencias de Flores no son demasiado precisas; hemos podido comprobar que, generalmente, llama "tanto" a las estelas piramidades, pero también que, en ocasiones, designa con el mismo término a algunos altares como, por ejemplo, al de la tumba 986,4: cf. cuaderno 952-986, hoja 38 vuelto a 41 recto, cuartillas 4 y 5 y croquis donde puede leerse: "Este tanto de piedra está enlucido de yeso blanco". Siret utiliza a veces la misma palabra para registrar el hallazgo de estelas en los inventarios. El uso de este término para designar tales objetos, quizá tenga que ver con que en algunos lugares se llamen "tantos" los mojones que delimitan las fincas, acepción que se relaciona con la que recoge Alcalá Venceslada (1980): “Señal que se pone para la medición” (en agrimensura). Corominas y Pascual (1980-1983, por su parte, recogen el aragonés tantonico como equivalente a adoquín.

20. Flores la dibuja con forma triangular y extremo apuntado: Cuaderno 390-413, hoja 37 recto, hoja 38 vuelto.

21. Según descripción de Flores, Cuaderno 449-478, hoja 20 vuelto, hoja 21 recto.

22. En un croquis que suponemos hecho por Siret, aparece el n 511 con interrogación sobre una estela piramidal.

23. Astruc, 1951:50, anota que "tres estelas de piedra, recubiertas de yeso, se alzaban sobre las tres fosas más largas. De forma piramidal con base rectangular"; se refiere a sepulturas del grupo F, pero no da más detalles. Por lo que hemos podido averiguar, de las tumbas de este grupo tenían estelas la 321, 530, 572 y 710 . Dado que la 530 proporcionó dos estelas sencillas, podemos pensar que las piramidales corresponden a las tres restantes; de hecho, el no 321 figura sobre una pieza de este tipo en un croquis que calca una fotografía muy deteriorada de un conjunto en el que pueden distinguirse muchos de los monumentos en piedra hallados en Villaricos. En la misma autora, pág. 69, nota 476, encontramos argumentos para sugerir el 
Como puede comprobarse en el Cuadro 1, en su mayor parte estas estelas proceden de enterramientos de inhumación, sobre todo del grupo C $(460,462,511,513$, etc.), pero también se encontraron en tumbas de incineración $\left(358,612^{24}\right.$ y 717$)$. Es interesante observar cómo estas piezas que, además de señalar la sepultura, pudieron tener un carácter simbólico más profundo (Tore, 1971-72b: 262)-, se encuentran también en los enterramientos practicados dentro de cámaras hipogeas $(556,560$, etc.), es decir, en un medio en el que sólo resultaban visibles para el que accediera a la cripta; en cualquier caso, siempre debieron estar en el exterior del enterramiento propiamente dicho, quizá en la cabecera como anotó Flores para la Tumba 321 (Fig.3:nº1).

La cronología de estos monumentos sólo podrá ser precisada cuando se lleve a cabo un estudio pormenorizado de los objetos que componían el ajuar de cada sepultura ${ }^{25}$. Nosotros hemos intentado clasificar las ánforas de las tumbas 460 y 462 a partir de las ilustraciones de Flores y pensamos que podrían corresponder al tipo III de M ${ }^{a}$ J. Almagro; de ser así, habría que asignarles una cronología de fines del V y, sobre todo, del IV a.C. (M J. Almagro Gorbea, 1986b:274 y fig.3). Ratifica esta datación la presencia en estas mismas sepulturas de huevos de avestruz que se han fechado entre los siglos VI-IV a.C. (San Nicolás, 1975:98) ${ }^{26}$. El hipogeo 556 tuvo un período de utilización amplio y dió materiales que se fechan entre el IV a.C. y el siglo II de J.C. (Mª J. Almagro Gorbea, 1986a:633). Finalmente, la tumba 612 confirma la perduración de estas estelas en Villaricos hasta época romana, pues los restos quemados se cubrieron con un ánfora de inequívoca adscripción a ese período.

Los monumentos funerarios de forma piramidal son muy conocidos en el mundo púnico y presentan una gran variedad (Cid Priego,1949: 91-126). Las pirámides como las de Villaricos son el tipo más sencillo y más extendido. Piezas similares se encontraron en tumbas de Ibiza (Gómez Bellard, 1990: 111-114 y láms. LVII y LX) y de Cádiz (Perdigones, Muñoz y Pisano, 1990: 37, nota 10, y 49; quizá también Quintero Atauri, 1932: lám.III,B), de los siglos VI y V a.C., respectivamente. En el Mediterráneo Central las conocemos tanto en santuarios (cf. v.g., para Tharros: Moscati y Uberti,1985:láms.IV.13 y V:16; para Mozia: Moscati y Uberti,1981,II: láms.VII:56 y VIII:57; para Sulcis: Bartoloni,1986: lám.I:6 y 7) como en contextos funerarios. De la necrópolis de Tharros procede una pieza idéntica a las de Villaricos (Tore,1971-72b: fig.3,11) y Tamburello (1967:362 y nota 2) encontró cipos en forma de pirámide truncada, simple o múltiple, en el interior de algunas sepulturas de Palermo fechadas en el siglo III a.C. La perduración de las estelas en forma de pirámide hasta época romana está atestiguada por los hallazgos realizados en la necrópolis de Sétif, con una cronología de los siglos II y III (Février y Gaspary,1966-67:46) y, sobre todo, en la de Tipasa. Lancel (1970: 187 y figs.33-35 y 39-40) supone que las pirámides debían coronar un pilar (Lancel, 1970: fig.38; cf. Belén, 1992-93: fig.4). Curiosamente también Siret (1906: 463 (87), nos.3 y 4) indica al describir dos de estas estelas que "probablemente estarían colocadas encima de otra piedra". Un cipo de la necrópolis de Tharros

\footnotetext{
hallazgo, asimismo, de estelas piramidales en la tumbas, 560 y 693 . Coinciden los datos deducibles de Astruc con que Flores escribió sobre la planta de la sepultura 560: "... y encima de la puerta en el centro una losa de tanto bañada de yeso": cuaderno 546-586, hoja 10 vuelto a 22 recto inclusive, cuartilla n 10 . En cuanto a la T. 693,8 indica que se hallaron " 2 tantos de barro": Cuaderno 683-710, hoja 13 vuelto a 20 recto, cuartilla 6 (cf. uso del término "tanto" en nota 19). En relación con la tumba 677, aparte del dibujo de Siret: fig.3:8, en el croquis de la tumba hecho por su capataz figura, en un extremo de la fosa $n^{0} 4$, un objeto triangular apuntado que suponemos que es la estela, aunque en el texto no se menciona el hallazgo de tal pieza. Por último, respecto a la T.1024, cf. nota 16.

24. Quizá por error, esta sepultura aparece en la obra de Astruc (1951:52) entre las inhumaciones del grupo G, pero la descripción de Flores dice con claridad que el cadáver estaba quemado: Cuaderno 587-624, hoja 27 vuelto, hoja 28 recto.

25. Un equipo que dirigía el Prof. M.Fernández-Miranda está terminando un estudio de conjunto de la Necrópolis de Villaricos.

26. Huevos de avestruz se hallaron también en las sepulturas $413 / 2,460,462,511,513,515$ y 601 .
} 
demuestra que Siret no estaba equivocado y que esta solución debió ser frecuente (Tore,1971-72b:fig.2,1), pero la reconstrucción de Lancel, al estilo de los pilares-estela, no nos parece desacertada tampoco, teniendo en cuenta que las gentes de Villaricos contaban con tradición en esta clase de monumentos funerarios. La esfinge hallada en este yacimiento (Chapa, 1985: 58 y 218) posiblemente coronaba también un pilar erigido sobre la sepultura de un personaje importante. La pieza, de características estilísticas afines al mundo fenicio, se ha fechado en los últimos años del siglo VII o principios del VI a.C., y la tumba de la que supuestamente formaba parte (Cf. Chapa, 1985: 221),se considera el prototipo de los monumentos ibéricos similares (AlmagroGorbea,M., 1983:17). Tampoco es difícil aceptar la propuesta del citado investigador francés, teniendo en cuenta las relaciones formales y simbólicas que existen entre las pirámides simples y aquellos otros monumentos monolíticos compuestos por un pedestal paralelepípedo con remate piramidal (Tore, 1971-72b: 249267), conocidos en Chipre (Tore,1971-72b: fig.4: $\mathrm{n}^{\circ} \mathrm{s} .1$ y 2), en el tofet de Cartago con cronología de los siglos VI-V a.C (Picard,1957: 130: Cb 357 y lám.XLIX) , en Mozia (Tore,1971-72b: fig.4,4) y en Tharros (Tore, 1971-72a: lám.XXVI y 1973b: lám.V,2). Monumentos similares se encuentran también en la necrópolis de Les Andalouses durante los siglos II-I a.C. (Vuillemot,1965: 290 y fig.124).

Pero, sin duda, la pieza más excepcional dentro de esta variante de estela piramidal la encontramos en la misma necrópolis de Villaricos. Mide unos 50 centímetros y presenta la particularidad de que sobre una de las caras del pilar de caliza, se esculpió la cabeza de un personaje masculino con tocado egipcio y en la opuesta un capitel eólico (Lám. V), como el que se halló en las proximidades del antiguo templo de Baal-Hammón en Cádiz (Marín Ceballos, 1984: 30-33). Lamentablemente esta estela carece de contexto original, ya que se reutilizó en la cubierta de la tumba no 521 (Astruc, 1951:175) que podemos fechar dentro del siglo IV a.C ${ }^{27}$. Se ha señalado insistentemente su inspiración en el arte chipriota del período en que Egipto deja sentir más intensamente su influencia sobre la isla (Astruc, 1951: 175; Bisi,1966: 43-45) ${ }^{28}$. La datación que se le asigna dentro del siglo VI a.C. (Bisi, 1966:44), convierte a esta pieza, junto con la esfinge ya citada, en el monumento funerario más antiguo de Villaricos.

3. Altares. En este grupo entran monumentos de muy diferente morfología pero, supuestamente, de idéntica función; desde los simples bloques someramente desbastados (Fig.4: $\mathrm{n}^{\circ} 5$ ) a ejemplares que presentan mesa y pie individualizados (Fig.4: $\mathbf{n}^{\mathbf{0} 6}$ ). El lote más importante ${ }^{29}$ lo componen piezas que tienen en común poseer forma troncopiramidal, con moldura y gola que se desarrollan sólo en el frente y en las paredes laterales, quedando la espalda vertical y lisa. En la parte superior presentan una cavidad rectangular, generalmente poco profunda. Están hechas con arenisca, salvo alguna que se labró en piedra caliza, y estuvieron enlucidas con una capa de yeso blanco. Aún respondiendo a las mismas características formales del conjunto, una de las piezas presenta las esquinas de la cara frontal rebajadas y pintadas de rojo al igual que la moldura (Fig.4:nº 2 y lám. VI).

Las dimensiones son muy variables, oscilando la altura máxima entre los 65 y los 20 centímetros, aunque la media se mueve entre los 25-35 centímetros.

Se hallaron monumentos de estas características sólo en enterramientos de inhumación, en fosas (№s.

27. Flores hizo un dibujo muy ingenuo de la pieza e indicó : "En la parte de la cabeza tres pedazos de piedra de cantería que ha sido una estatua con dibujos en la espalda y encima de las cubiertas unos pedazos de huevo de avestruz y un pedacillo de cobre y el cántaro ha estado encima de un poyo que tiene $60 \mathrm{cms}$. de largo y $20 \mathrm{cms}$. de alto unido con las piedras de la estatua ha habido escorias de horno de fundición el dibujo tiene pintura colorada" : Cuaderno 495-522, hoja 36 vuelto, 37 recto.

28. Sobre la influencia egipcia en la arquitectura religiosa fenicia cf. Bisi,1967: 191 y 202, y Wagner,1980.

29. En el M.A.N. contamos 11 altares en muy distinto estado de conservación, pero sólo hemos encontrado referencias al hallazgo de piezas de estas características en las tumbas que se citan más abajo. 
718,1024 y 1626) (Fig.5), o en el interior de cámaras (411/2 y 986/4) ${ }^{30}$ (Fig.6); estaban situadas en la cabecera y en el caso de los hipogeos parece que algunas estuvieron en el corredor, junto a la puerta de entrada al sepulcro. Tampoco en este grupo resulta fácil reconocer el ejemplar de cada tumba a partir de las notas de Flores, ya que ni siquiera parecen precisas las dimensiones que indica. Por otra parte, es muy posible que con el tiempo, las piedras blandas en que se trabajaron, hayan sufrido un deterioro que también dificultaría la identificación.

El altar de la tumba 411/2 se ha reconocido sin problemas cotejando el dibujo que de él hizo Siret (Fig.6:nº3) con las piezas conservadas en el M.A.N. (Lám. IX), pero ninguna otra pieza se puede identificar con total seguridad. La estela de la lámina VIII podría ser la hallada en la sepultura 1626 (cf. fig. 5:2), pues ambas presentan una fractura parecida en la parte inferior ${ }^{31}$. La estela de la sepultura $\mathrm{n}^{\circ}$ 986/4 tiene, según Flores, una altura de 36 centímetros, que coincide aproximadamente con la de la lámina no VII. Esta última es el único ejemplar que carece de cavidad en la cara superior, pero consideramos que debe incluirse en este mismo grupo. Uno idéntico se halló supuestamente en Riotinto (Huelva)(García y Bellido, 1942: cf.80 y 294) (Fig.7), otro centro minero importante que ya en el siglo VII a.C. albergaba posiblemente población de origen oriental.

Sin duda sobre estos monumentos se ofrecían libaciones y se quemaban perfumes. El de la tumba 411/2 presenta una acanaladura que, arrancando de la cavidad superior, recorre de arriba a abajo toda la parte posterior del monumento; por ella descendían hasta la tierra los líquidos que se vertían sobre el altar. Además, la cavidad presenta, sobre el fondo rayado con surcos verticales paralelos, una mancha roja producida por el calor del fuego. Una tenue mancha rojiza se aprecia también sobre la superficie plana de la estela de la lám. VII.

En el tophet de Tharros abundan los que llaman base-altar que son iguales a los que acabamos de citar. Moscati y Uberti (1985:25 y 32-33) les reconocen la misma función que a las estelas con trono y en su opinión servirían de soporte a una imagen, icónica o antropomorfa. Otros autores consideran, por el contrario, que debe diferenciarse entre altar y basamento, ya que su función sería distinta (Tore,1971-72a:188). Un ejemplar de la necrópolis de Tharros, datado en el siglo IV a.C., deja claro que además de utilizarse en rituales de libación o para quemar esencias aromáticas, estas piezas están concebidas también como auténticas estelas funerarias, pues en el frente se grabó un epitafio dando cuenta de la identidad del difunto enterrado en aquella sepultura (Uberti,1986: 115 y fig.156).

Las estelas o cipos altares encuentran abundantes paralelos en Cartago, Sicilia y Cerdeña. G. Tore (197172a:118-119 y notas 61 y 63, 188 y láms. XIX-XXIV) relacionó los basamentos con gola egipcia de los cipotrono con los modelos más elementales conocidos en el Mediterráneo Central y en la Península Ibérica, y realizó una pormenorizada relación de paralelos que muestra la existencia de estos monumentos tanto en los cementerios (Cartago, Palermo, Tharros, Cagliari), como en los santuarios (Cartago, Tharros). A esta relación podríamos añadir los ejemplos documentados en las colecciones de los tophets de Mozia (Moscati y Uberti, 1981: II, fig. 55 y lám. CLXXXVI: 1012-1014) y de Sulcis (Bartoloni, 1986: lám.III:21-24). Para terminar, no podemos dejar de mencionar el pedestal con pila de la tumba 2 de la necrópolis de Trayamar (Málaga), de un momento avanzado del siglo VII a.C (Schubart y Niemeyer,1976:129-130, 231-232 y 237); aunque morfológicamente la pieza es diferente ${ }^{32}$, consideramos que constituye un precedente claro de la utilización de estas estelas-altares en las colonias fenicias de la Península Ibérica.

30. A juzgar por el dibujo de Flores, podría incluirse en este grupo la estela de la sepultura 1008, pero no podemos asegurarlo: Cuaderno 987-1024, hojas 23 vuelto y 24 recto.

31. En las notas de P.Flores sobre la tumba 1626 , no figuran las dimensiones de la estela y la fractura está representada en el lado contrario, como puede observarse. La altura de esta pieza coincide, aproximadamente, con la que el autor da para una - ¿el altar?- de las de la T. 1024, pero no la anchura ni el grosor.

32. Tiene paralelos en el mundo púnico: cf. una pieza del s.V-IV a.C. procedente del tophet de Cartago, en Ribichini,1988: 105 y 614 , catálogo n² 179 . 
Los altares de Villaricos deben fecharse durante los siglos V y IV a.C. Las tumbas nºs. 718,1024, y 1626, tenían ánforas que por asimilación a los tipos I y III de Mํㅗ. J. Almagro (1986b: 270-274, figs. 2 y 3), pensamos que podrían tener esa cronología; esta última sepultura y la n⿳0 411/2 tienen también huevos de avestruz que no se conocen en el yacimiento después del siglo IV a.C. (San Nicolás, 1975:98).

4. Siret (1906:fig.18 y lám.XX,5) encontró otros monumentos en piedra en la necrópolis ${ }^{33}$, pero sólo mencionaremos una pieza que Astruc (1951:81-82, lám.L,5) describe como “un gran cipo piriforme", hecha en piedra caliza, con una muesca en la base y otra en la parte superior. La forma recuerda la de los betilos que presiden los altares-trono de Cartago (Lézine, 1960:37, figs.18 y 20) o Tharros (Moscati y Uberti, 1985,II: láms. LVIII:147; LXI:149; y LXII:149-150). La perduración hasta época romana de altares con betilo de forma ovoide está atestiguada en la necrópolis de Tipasa. Lancel (1970:187 y fig.40 bis) emparenta este monumento con el obelisco rematado con un elemento ovoide de la necrópolis romana de Baelo (Cádiz) (Paris y Bonsor, 1926: fig.21). La pieza de Villaricos se erigiría también muy probablemente sobre un pedestal, en el exterior de una cámara hipogea (Astruc,1951:81).

\section{OBSERVACIONES}

En muchas de las necrópolis púnicas del Mediterráneo centrooccidental, se han hallado monumentos en piedra, estelas o cipos sobre las sepulturas. Sin embargo, la investigación se ha volcado sobre todo hacia el estudio de las estelas votivas, mucho más numerosas y con un repertorio iconógráfico incomparablemente más rico. Pero en uno u otro contexto, estos monumentos no parecen corrientes antes del siglo VI a.C (BenichouSafar,1982:71; Bisi, 1967:228; Moscati y Uberti, 1981:57 y 1985:51). En las necrópolis fenicio-púnicas más occidentales, tampoco conocemos estelas funerarias anteriores. Del s.VI a.C., son los sencillos ejemplares anicónicos de la necrópolis de Ibiza (Gómez Bellard, 1990: 95,97,113, y láms. XXVIII-XXIX, XXXIV, LVII y LX). En Villaricos parece que no se encontraron en las tumbas de los grupos A y B, que Astruc fechó en ese mismo siglo ${ }^{34}$, pero la estela con prótomo humano y la esfinge a que hemos hecho referencia, indican que por esas fechas se conocían ya monumentos que se superponían externamente a las sepulturas. El carácter de tales monumentos quizá indique que la costumbre de señalar las sepulturas con algo más elaborado que unas simples piedras erectas, era poco corriente.

La mayor parte de las estelas que aquí hemos revisado, corresponden a la etapa de mayor desarrollo del poblado, que se fecha durante los siglos V y IV a.C.

Los monumentos sencillos en forma de pirámide que seguramente poseen, además, carácter betílico (Tore, 1971-72b:262), se encontraron con más frecuencia en enterramientos de inhumación, pero también había estelas de este tipo en algunos de incineración; estas últimas podrían ser, en general, más tardías y en algún caso se pueden fechar con seguridad en época romana.

Los altares se hallaron exclusivamente en sepulturas de inhumación, tanto en fosas simples como en cámaras hipogeas. Generalmente se halló sólo una estela por enterramiento, aunque en algúna tumba se encontraron varias ${ }^{35}$.

33. En la tumba 411/2, se halló además del altar ya mencionado otra pieza tallada en piedra: cf.fig.6:2.

34. La única excepción serían las "piedras empinadas" de la tumba 583, que hemos mencionado más atrás: Cuaderno 546-586, hoja 34 vuelto.

35. Cf. Cuadro 2. Nos referimos naturalmente a las tumbas individuales, como la 530 o la 1024; es lógico que en las cámaras hipogeas se hallaran varias estelas, como hemos documentado en la 556, 560 y 693. 
Ninguna de las estelas documentadas se asocia a enterramientos de niños, pues ya indicábamos más atrás que la tumba $\mathrm{n}^{\mathrm{0}}$ 612, que Astruc clasifica como inhumación infantil, está descrita con claridad por Flores que refiere la existencia de "unos restos de un cadáver quemado en un local como cuevacho y tapados con medio cántaro" 36. Esto descarta que alguna de las piezas pudiera ser votiva y estar relacionada con sacrificios de niños. Las estelas de Cádiz (Marín Ceballos,1984:38) y de Ibiza (Almagro Gorbea, 1967:11) que se han venido considerando como pruebas de la existencia de sacrificios infantiles, debían ser también monumentos funerarios dado el contexto en que se hallaron (Quintero Atauri,1932:7-8; $\mathrm{M}^{\mathrm{a}} \mathrm{J}$. Almagro Gorbea, 1967:5; Gómez Bellard,1990:147). No queremos insinuar con ésto que no existieran tofets en las colonias de Occidente; posiblemente los hubo, pero de momento carecemos de documentación al respecto. El culto a la divinidad femenina que tutela estos santuarios está, al parecer, atestiguado en muchas ciudades costeras del litoral mediterráneo español (Marín Ceballos, 1987:43-79). Tanit era venerada en cuevas en Ibiza (Aubet, 1986:622623), en Villaricos ${ }^{37}$ y en Cádiz (Marín Ceballos,1984:15-16), las tres ciudades mencionadas aquí por los hallazgos de estelas funerarias; en ésta última, además, existía un templo dedicado a Baal-Hammón (Marín Ceballos, 1984:30). Pero falta la documentación arqueológica de la práctica de sacrificios cruentos, si exceptuamos los niños inmolados, supuestamente, en Cádiz durante el siglo I a.C.

La utilización de monumentos en piedra colocados sobre las tumbas por la población púnica de Villaricos, estuvo seguramente propiciada por la introducción de ideas religiosas que comportaron cambios importantes en los rituales funerarios. Estas transformaciones afectaron a todo el mundo púnico a partir del siglo VI a.C (Aubet,1986:612-613) y conllevaron una sorprendente uniformidad de los rituales de tratamiento del cadáver, de la arquitectura funeraria o de la tipología de los monumentos exteriores, en todos los establecimientos púnicos del Norte de África y del Mediterráneo Central y Occidental. Algunos autores (Aubet, 1986:623) ven en tal unificación de creencias religiosas, una imposición ideológica y política por parte de Cartago.

En todos estos territorios, el sustrato púnico sigue manifestándose con fuerza todavía en época romana avanzada. El hecho se hace patente en múltiples aspectos que aquí no podemos detallar pero, muy concretamente, en el de las prácticas funerarias. En Cerdeña (cf.v.g, Moscati, 1988:326; Uberti,1986: 127, figs.181182), en el Norte de África (Gauckler, 1915,II:334-343); Lancel,1970:206) o en Andalucía, los cementerios, ofrecen pruebas de que algunas tradiciones se mantuvieron después de muchos años. Ya nos hemos referido a lo largo de estas páginas a la pervivencia de costumbres púnicas en las tumbas de época romana de Villaricos y de Cádiz, pero no está de más recordar que no son los únicos ejemplos ${ }^{38}$. Las señas de identidad de la población púnica se manifiestan igualmente con fuerza en las necrópolis de Belo (Paris y Bonsor, 1926:110; Remesal,1979:49) o de Carmona (Bendala,1976: 38 ss.; Belén,1983: 217). En esta última, los primeros grupos de orientales debieron asentarse en fechas tempranas, quizá a fines del siglo VIII a.C. Con el tiempo la ciudad se convirtió en un centro importante para los intereses cartagineses en el Valle del Guadalquivir.

\section{BIBLIOGRAFÍA}

ALCALÁ VENCESLADA, A. (1980): Vocabulario Andaluz. Madrid, Gredos (Reimpresión).

36. Cuaderno 587-624. Hoja 27 vuelto, 28 recto.

37. Astruc (1951:179) refiere que Siret encontró una cueva santuario con la cual habría que relacionar quizá la favissa en que se hallaron abundantes pebeteros en forma de cabeza femenina ( $\mathrm{M}^{\mathrm{a}} \mathrm{J}$. Almagro Gorbea, 1983). En una escultura muy maltrecha (Siret,1906,fig.18) procedente de la necrópolis, puede reconocerse una figura femenina sentada sobre trono; a veces se han considerado estas figuras representaciones de la diosa Tanit (Marín Ceballos y Corzo, 1991:1031-1034).

38. A este respecto, cf. también Koch, 1976. 
ALMAGRO GORBEA, M J. (1967): Excavaciones arqueológicas en Ibiza. Excavaciones Arqueológicas en España,56. Madrid, Ministerio de Educación y Ciencia.

— (1983): "Un depósito votivo de terracotas de Villaricos", Homenaje al Prof.Martín Almagro Basch II:291307. Madrid, Ministerio de Cultura.

- (1984): La necrópolis de Baria. Excavaciones Arqueológicas en España, 129. Madrid, Ministerio de Cultura.

- (1986a): "Excavaciones en la necrópolis púnica de Villaricos", Homenaje a Luis Siret : 625-637. Sevilla, Consejería de Cultura, Junta de Andalucía.

- (1986b): "Las ánforas de la antigua Baria (Villaricos)", en G. del OLMO,G. y Mª E. AUBET (edts.): Los fenicios en la Península Ibérica I: 265-283. Sabadell, Ausa.

ALMAGRO-GORBEA,M. (1983): "Pilares-estela ibéricos", Homenaje al Prof. Martín Almagro Basch III: 720. Madrid, Ministerio de Cultura.

ASTRUC,M. (1951): La Necrópolis de Villaricos. Informes y Memorias, 25. Madrid, Comisaría General de Excavaciones Arqueológicas, Ministerio de Educación Nacional.

AUBET, Mㄹ E. (1986): “La Necrópolis de Villaricos en el ámbito del mundo púnico peninsular”, Homenaje a Luis Siret: 612-623. Sevilla, Consejería de Cultura, Junta de Andalucía.

- (1987): Tiro y las colonias fenicias de Occidente. Barcelona, Ed. Bellaterra.

BARTOLONI,P. (1986): Le Stele di Sulcis. Catalogo. Collezione di Studi Fenici, 24. Roma, CNR.

BELÉN,M. (1983): “Aportaciones al conocimiento de los rituales funerarios en la necrópolis romana de Carmona", Homenaje al Prof.Martín Almagro Basch III:209-226. Madrid, Ministerio de Cultura.

- (1992-93): "Religiosidad funeraria en la necrópolis prerromana de Cádiz", Tabona VIII (2): 351-371.

BENDALA,M. (1976): La necrópolis romana de Carmona (Sevilla). Sevilla. Public. de la Excma. Diputación Provincial.

BENICHOU-SAFAR, H. (1982): Les tombes puniques de Carthage. Topographie, structures, inscriptions et rites funéraires. Paris, Études d'Antiquité Africaine, CNRS.

BISI,A.Má. (1966): Kipriaka. Contributi allo studio della componente cipriota della civiltá punica. Roma, Gherardo Casini.

- (1967): Le Stele Puniche. Studi Semitici, 27. Roma, Istituto di Studi del Vicino Oriente, Università di Roma.

BLÁZQUEZ, J.Mํ. (1983): Religiones Prerromanas, en Primitivas religiones ibéricas II. Madrid, Cristiandad.

CARRILERO, M. y otros. (1993): "La colonización fenicia en el Sureste de la Península Ibérica", Actas del I Coloquio de Historia Antigua de Andalucía, Córdoba, 1988, I: 95-105. Córdoba, Monte de Piedad y Caja de Ahorros de Córdoba.

CID PRIEGO, C. (1949): "El sepulcro de torre mediterráneo y sus relaciones con la tipología monumental", Ampurias XI:91-126.

COROMINAS,J. y PASCUAL, J.A. (1980-1983): Diccionario crítico etimológico castellano e hispánico. Madrid.

CORZO,R. (1989): "Los sacrificios infantiles en Cádiz",en Inhumaciones infantiles en el ámbito mediterráneo español (siglos VII a.E. al II d.E.). Cuadernos de Prehistoria y Arqueología Castellonense 14: 239-246.

CORZO,R. y FERREIRO, M. (1987): "Sacrificios humanos en el Cádiz antiguo", Actas del II Congreso Andaluz de Estudios Clásicos. Antequera-Málaga, 24-25 mayo de 1984, II: 57-61. Málaga, Universidad de Málaga.

CHAPA,T. (1985): La escultura ibérica zoomorfa. Madrid, Ministerio de Cultura.

FÉVRIER,P.A. y GASPARY,A. (1966-67): "La Nécropole Orientale de Sétif. Rapport préliminaire sur les fouilles effectuées de 1959 à 1964”, Bull. d’ Archéologie Algérienne II: 11-93. 
FUENTES ESTAÑOL,Mํㅗ. (1986): Corpus de las inscripciones fenicias, púnicas y neopúnicas de España. Barcelona, Autora.

GARCÍA Y BELLIDO, A. (1942): Fenicios y cartagineses en Occidente. Madrid, CSIC.

GAUCKLER,P. (1915): Nécropoles Puniques de Carthage. Paris, Picard.

GÓMEZ BELLARD, C. (1990): La Colonización fenicia de la Isla de Ibiza. Excavaciones Arqueológicas en España, 157. Madrid, Ministerio de Cultura.

GONZÁLEZ WAGNER,E.C. (1983): Fenicios y cartagineses en la Península lbérica: ensayo de interpretación fundamentado en un análisis de los factores internos. Tesis doctorales de la Universidad Complutense, 30/83. Madrid, Universidad Complutense.

GUZZO AMADASI,Mํㅗㄹ G. (1978): "Remarques sur la présence phénico-punique en Espagne d'après la documentation épigraphique", Actes II Congrès International d'Étude des Cultures de la Méditerranée Occidentale: 33-42. Alger, Societé Nationale d'Édition et de Diffusion.

KOCH, K.M. (1976): "Observaciones sobre la permanencia del sustrato púnico en la Península Ibérica", Actas del I Coloquio sobre lenguas y culturas prerromanas de la Península Ibérica, Salamanca, 1974: 191-199. Salamanca, Universidad de Salamanca.

LANCEL,S. (1970): "Tipasitana IV: La nécropole romaine occidentale de la porte de Césarée: Rapport préliminaire”, Bull. d' Archéologie Algérienne IV:149-266.

LEVI, D. (1950): "La Necropoli Puniche di Olbia", Studi Sardi 9: 5-120.

LÉZINE,A. (1960): Architecture Punique. Recueil de documents . Pub. de l'Université de Tunis. Faculté des Lettres. $1^{\mathrm{er}}$ Série: Archéologie, Histoire, V. París. Presses Universitaires de France.

MARIN CEBALLOS,M M C. (1984): "La religión fenicia en Cádiz", en Cádiz en su Historia. II Jornadas de Historia de Cádiz.Abril de 1983: 5-41. Cádiz, Caja de Ahorros de Cádiz.

- (1987): “¿Tanit en España?”, en Lucentum VI:43-79.

MARIN CEBALLOS, Ma C. y CORZO,R. (1991): "Escultura femenina entronizada de la necrópolis de Cádiz",Atti Il Congresso Intern. Studi Fenici e Punici III: 1025-1038. Roma, CNR.

MOSCATI,S. (1988): "Le Stele”, en S. MOSCATI (Dir.): I Fenici: 304-327. Milán, Bompiani.

MOSCATI,S. y UBERTI, Mํㅡ. L. (1981): Scavi a Mozia. Le Stele. Pub. del Centro di Studio per la Civiltà fenicia e punica, 23; Serie Archeologica, 25. Roma, CNR.

- (1985): Scavi al Tofet di Tharros: I Monumenti lapidei. Coll. di Studi fenici, 21. Roma, CNR.

PARIS,P. y BONSOR,G. (1926): Fouilles de Belo (Bolonia, province de Cádix, 1917-1921). II. La Nécropole. Bordeaux, Bibliothèque de l'École des Hautes Études Hispaniques.

PERDIGONES,L., MUÑOZ,A., y PISANO,G. (1990): La necrópolis fenicio-púnica de Cádiz. Siglos VI-IV a.C. Studia Punica,7. Roma, II Università degli Studi di Roma. Dipartamento di Storia.

PICARD,C.G. (1957): Catalogue du Musée Alaoui. Nouvelle Série. Collections Puniques, 1. Tunis, Institut des Hautes Études de Tunis.

QUINTERO ATAURI,P. (1932): "Excavaciones en Cádiz. Memoria de las excavaciones practicadas en 19291931", Memorias de la Junta Superior de Excavaciones y Antigüedades, 117:4-28.

REMESAL,J. (1979): La Necrópolis Sureste de Baelo. Excavaciones Arqueológicas en España, 104. Madrid, Ministerio de Educación y Ciencia.

RIBICHINI,S. (1988): "Le credenze e la vita religiosa", en S. MOSCATI (Dir.): I Fenici: 104-125. Milán, Bompiani.

RUIZ MATA,D. (1988): “El Castillo de D” Blanca. Yacimiento clave de la protohistoria Peninsular", Revista de Arqueología, 85: 36-48.

SAN NICOLÁS, Ma P. (1975): "Las cáscaras de huevo de avestruz fénico-púnico en la Península Ibérica y Baleares", Cuadernos de Prehistoria y Arqueología de la Univ. Autónoma de Madrid 2: 75-100. 
SCHUBART,H. (1982): “Asentamientos fenicios en la costa meridional de la Península Ibérica”, I Jornadas Arqueológicas sobre Colonizaciones orientales. Huelva Arqueológica VI: 71-99.

SCHUBART, H. y NIEMEYER,H.G. (1976): Trayamar. Los hipogeos fenicios y el asentamiento en la desembocadura del río Algarrobo. Excavaciones Arqueológicas en España, 90. Madrid, Ministerio de Educación y Ciencia.

SIRET,L. (1906): Villaricos y Herrerías. Antigüedades púnicas, romanas, visigóticas y árabes. Madrid, Ministerio de Cultura. (Edición facsímil realizada en 1985).

SOLA SOLÉ, J.M"a (1955): "Inscripciones fenicias de la Península Ibérica”, Sefarad, XV (1): 41-53.

TAMBURELLO,I. (1967): "Palermo. Necropoli: l'esplorazione 1953-54", Notizie degli Scavi di Antichità, Serie $8^{\mathrm{a}}, \mathrm{XXI}: 354-378$.

TORE,G. (1971-72a): "Due cippi-trono del Tophet di Tharros", Studi Sardi XXII : 99-248.

— (1971-72b): "Su alcuni amuleti di Tharros", Studi Sardi XXII: 249-268.

UBERTI,M" L. (1986): "Fenici e Punici in Sardegna", en A. ANTONA y otros, (eds): Il Museo Sanna in Sássari: 111-128. Sassari, Banco di Sardegna.

VUILLEMOT,G. (1965): Reconnaissances aux échelles puniques d'Oranie. Autun, Musée Rolin.

WAGNER, P. (1980): Der Ägyptische Einfluss auf die phönizische Architektur. Bonn, Rudolf Habelt. 


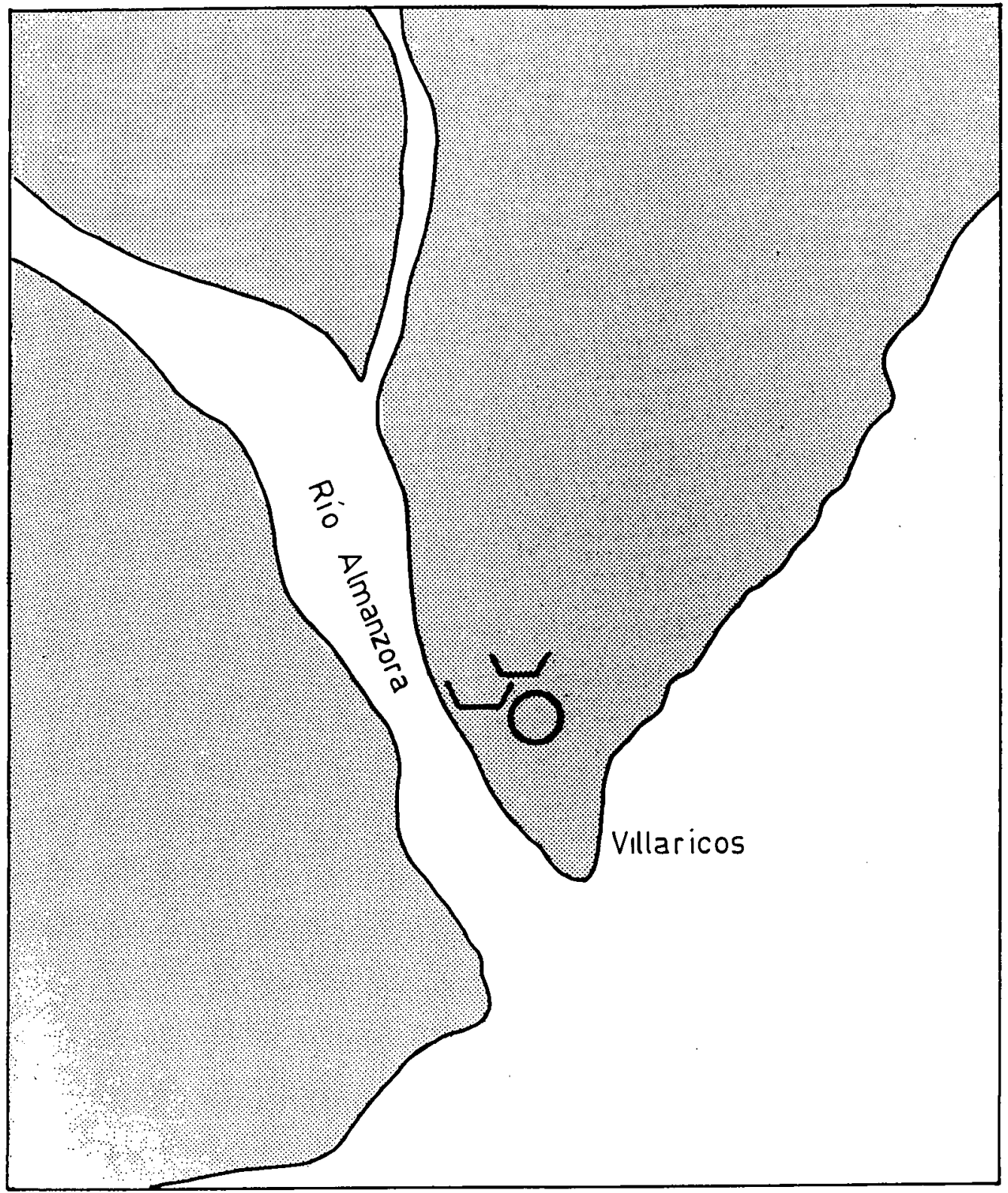

Fig. 1. Villaricos. El poblado (O) y la necrópolis ( $\smile$ ) púnica, sobre el río Almanzora. (Según H. SCHUBART,1982). 


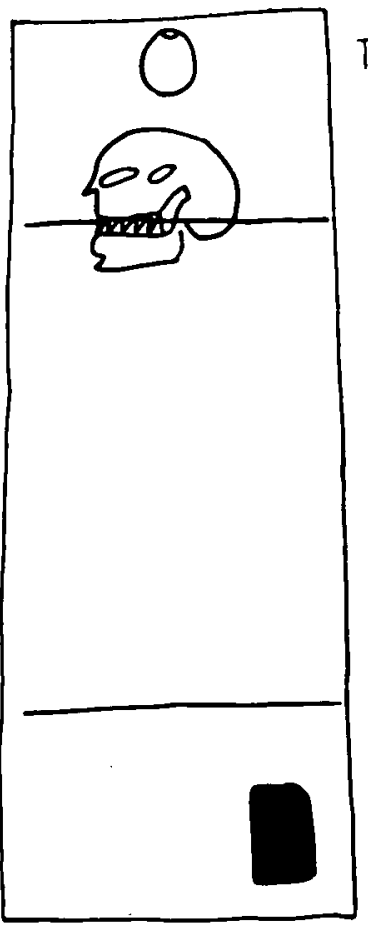

1

T. 841

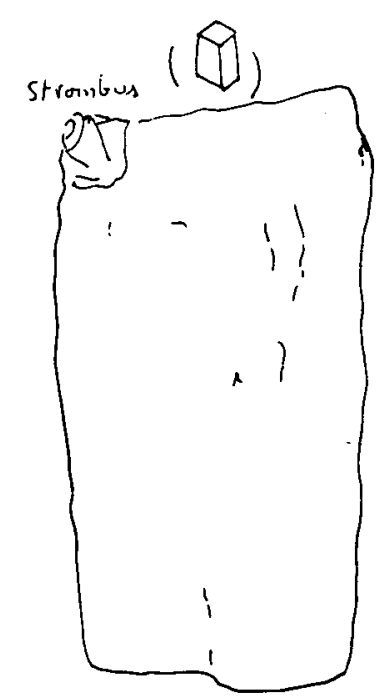

2

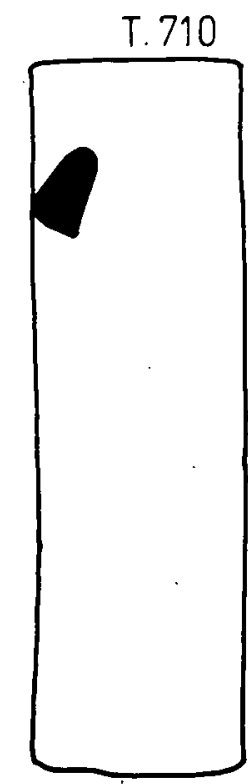

3
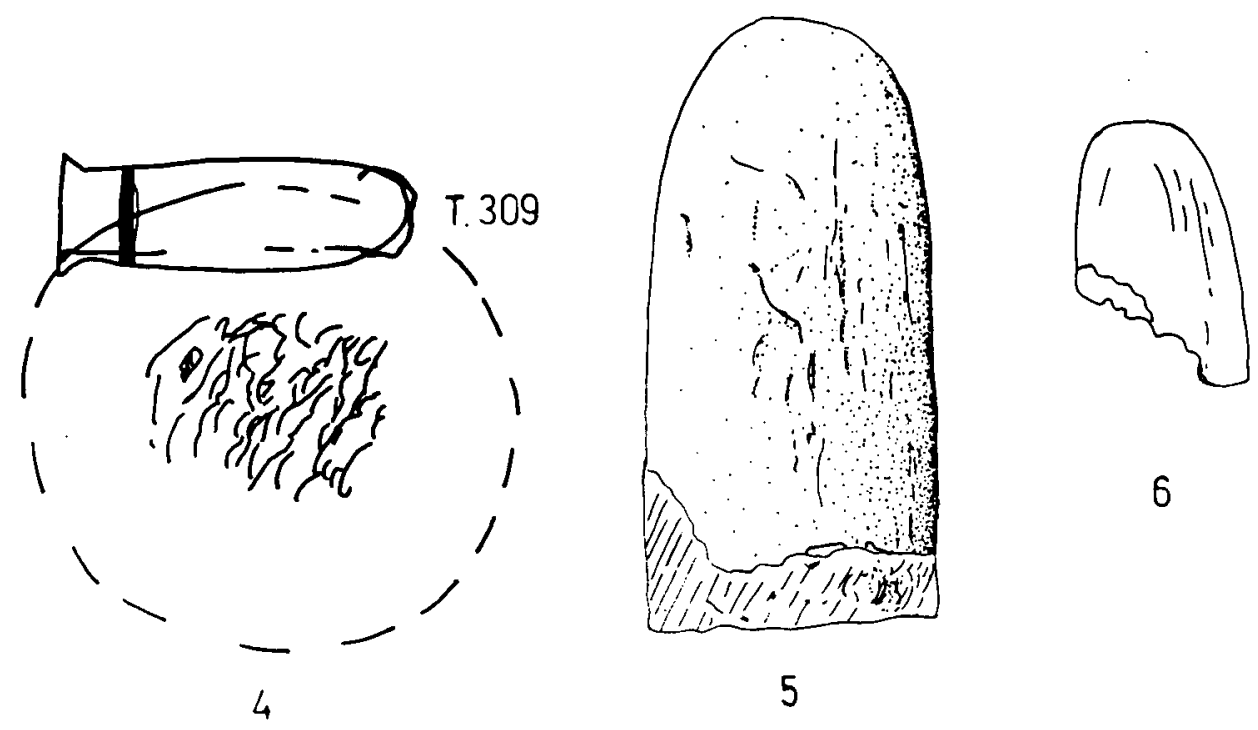

6

Fig. 2. Estelas de Villaricos: 1 y 3-4, a partir de originales de P.Flores; 2 y 5-6, a partir de originales de L.Siret. 

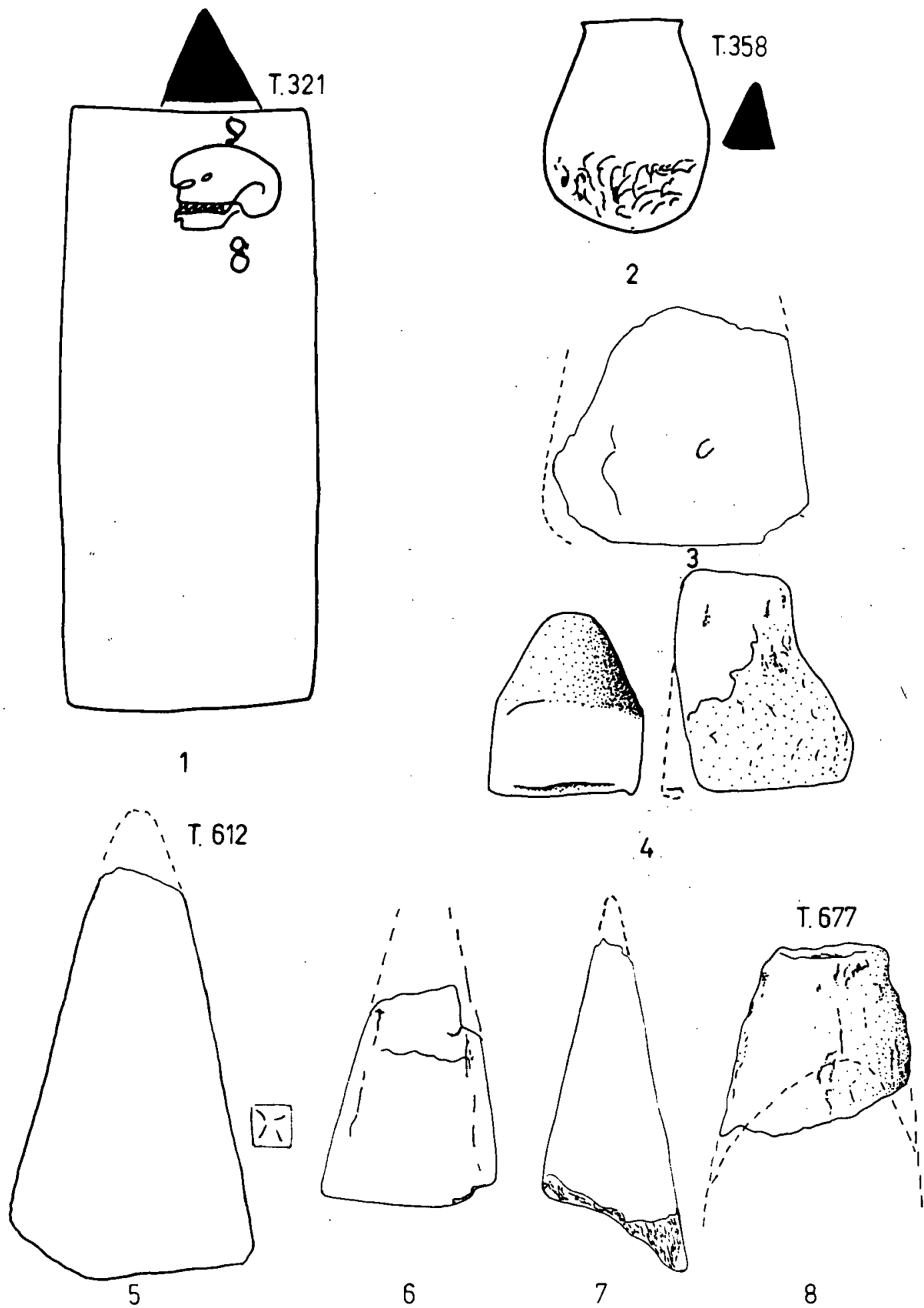

Fig. 3. Estelas de Villaricos: 1 y 2, a partir de originales de P.Flores; 3-8, a partir de originales de L.Siret. 

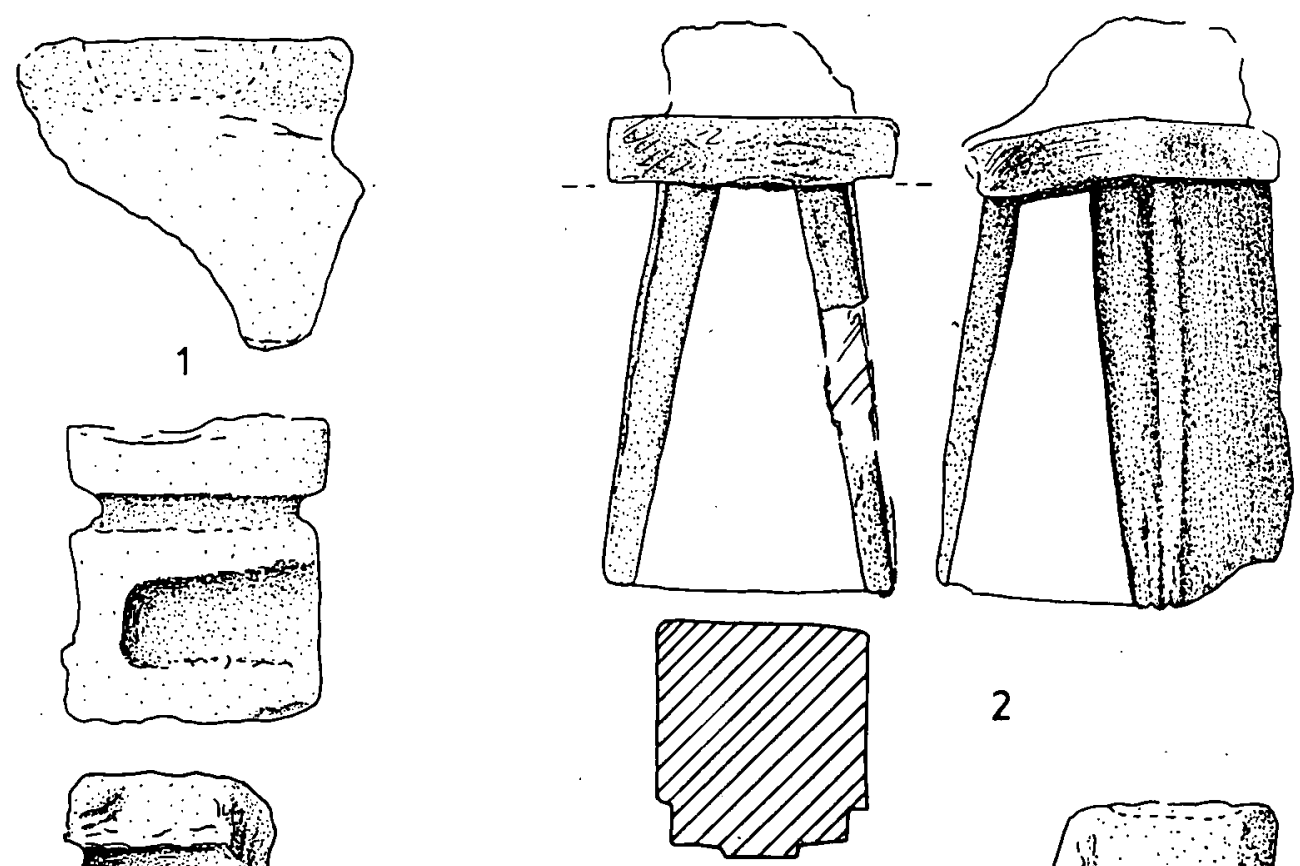

2

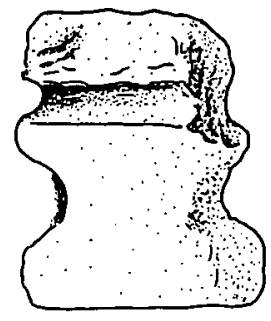

3
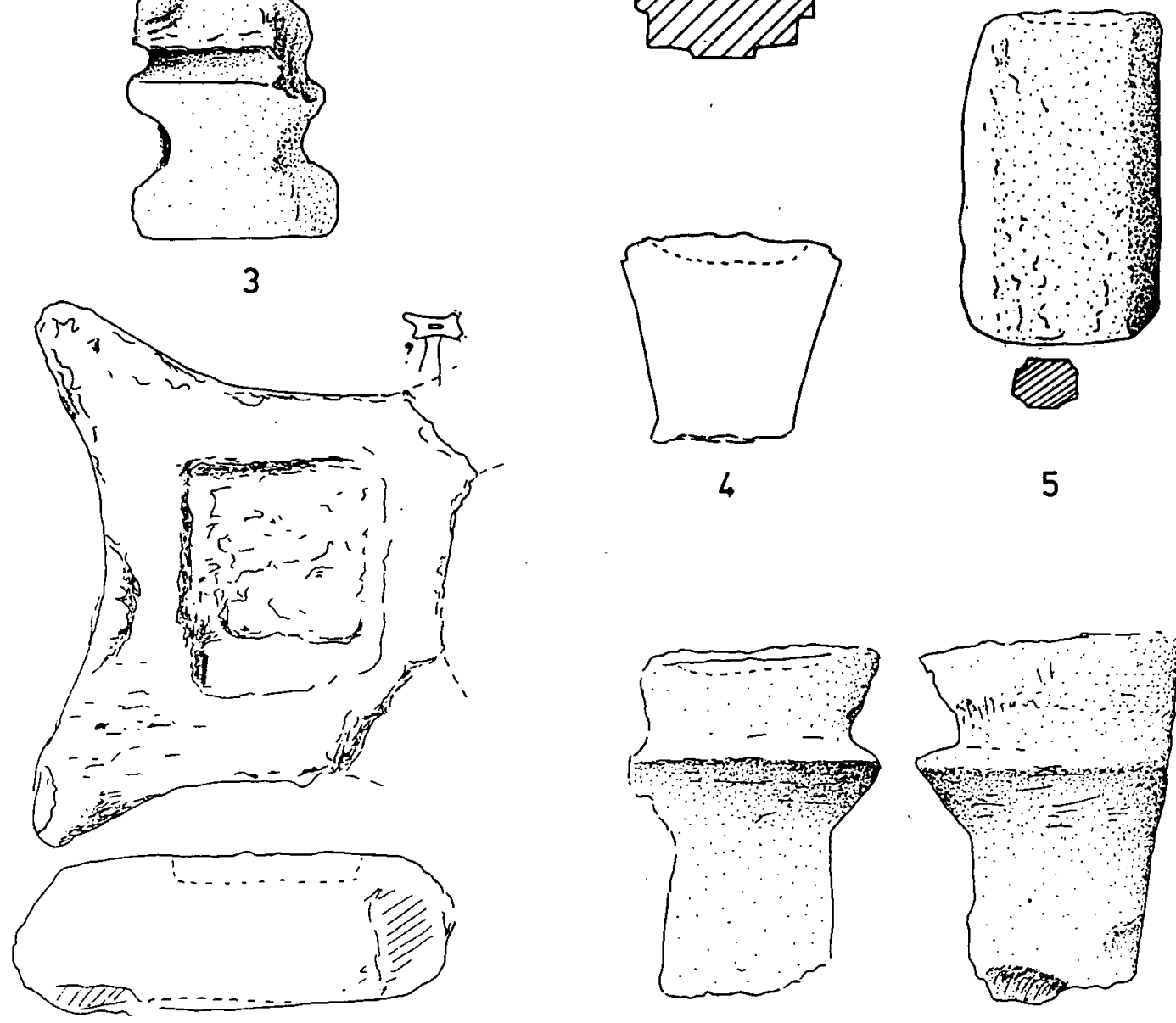

5
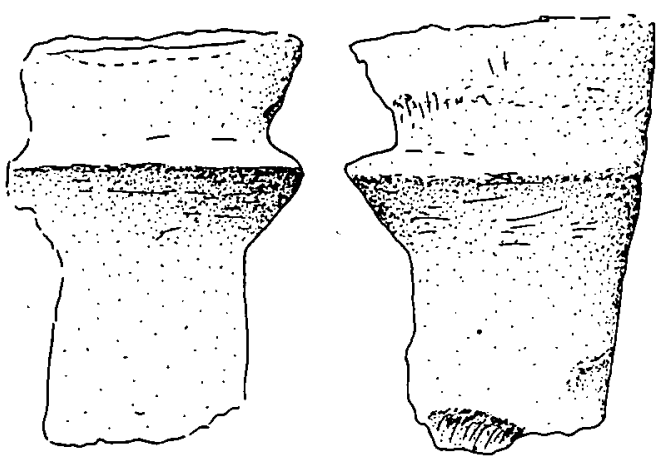

6

7

Fig. 4. Altares de Villaricos, a partir de originales de L.Siret. 


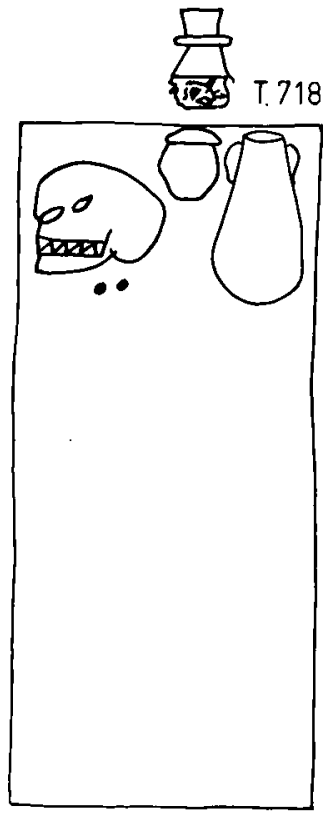

1

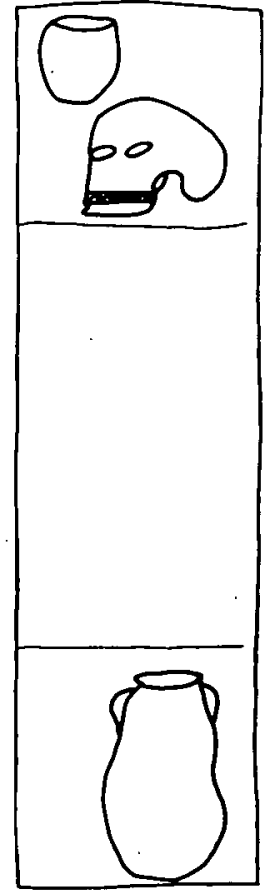

T. 1.626

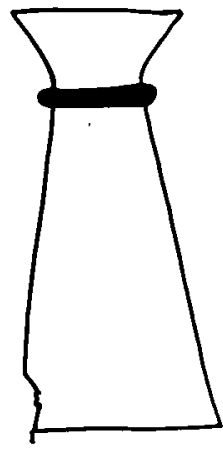

2

Fig. 5. Villaricos: Sepulturas de inhumación con altares. (A partir de originales de P.Flores).
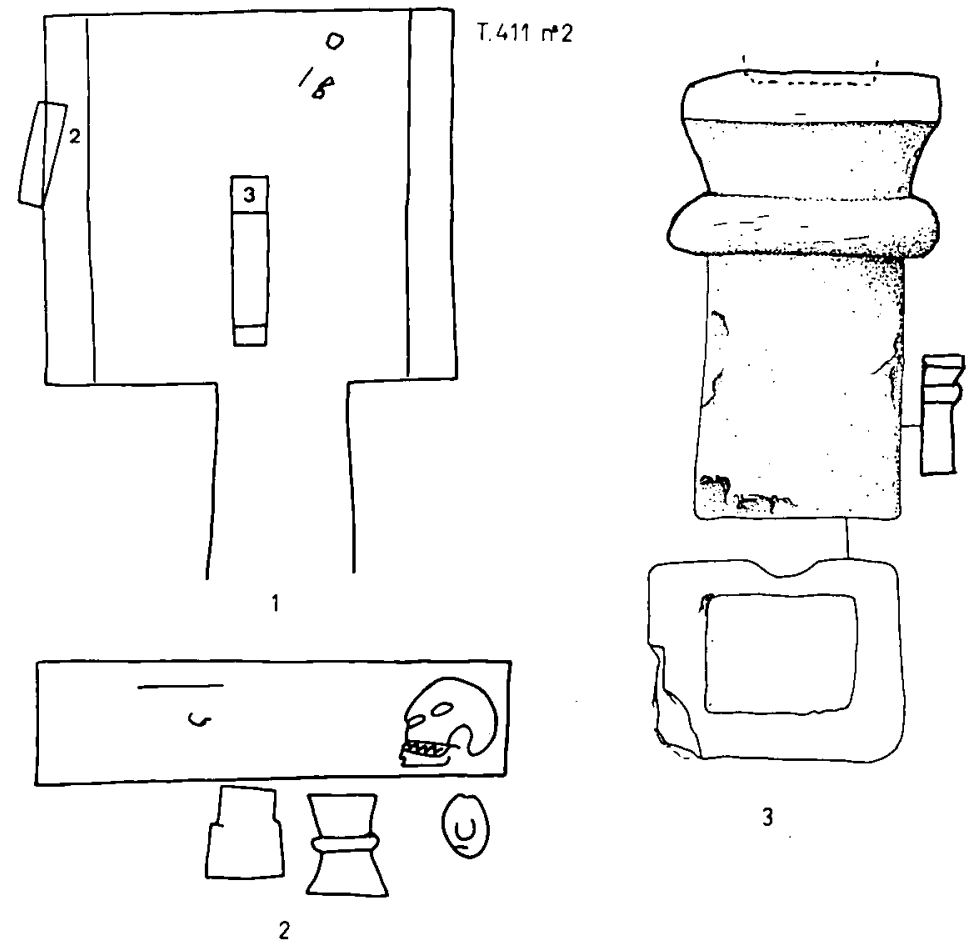

Fig. 6. Villaricos. Sepultura de inhumación con altar: 1 y 2, a partir de originales de P. Flores; 3, a partir de originales de L. Siret. 


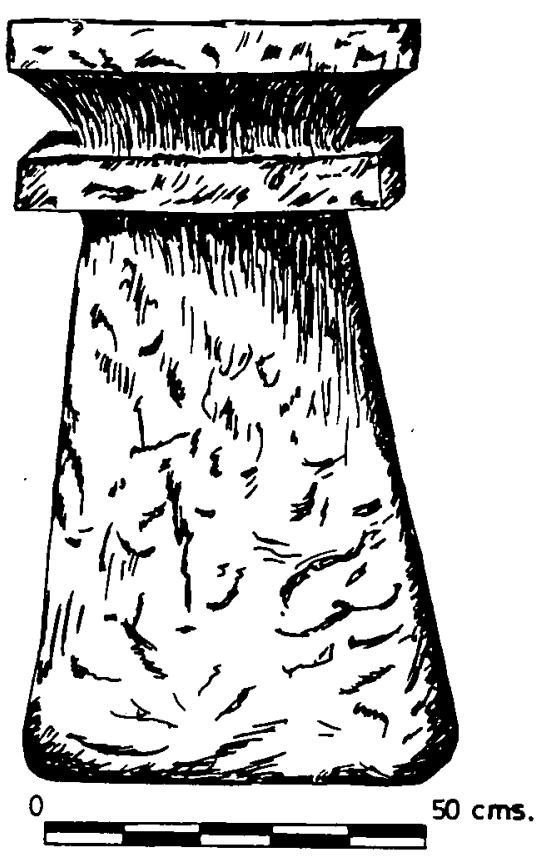

Fig. 7. Altar de Riotinto, Huelva. (A partir de original de A.García y Bellido, 1942). 


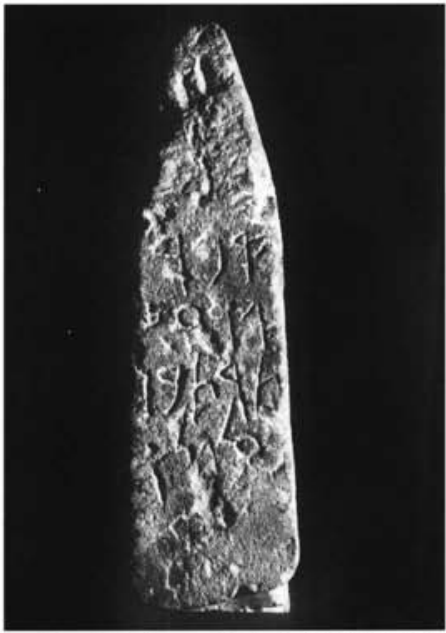

Lám. I. Estela con epitafio: Inve 1935/4.Vill/1. (Altura: $93 \mathrm{cms}$;; base: $27 \times 22 \mathrm{cms}$.). (Foto M.A.N)

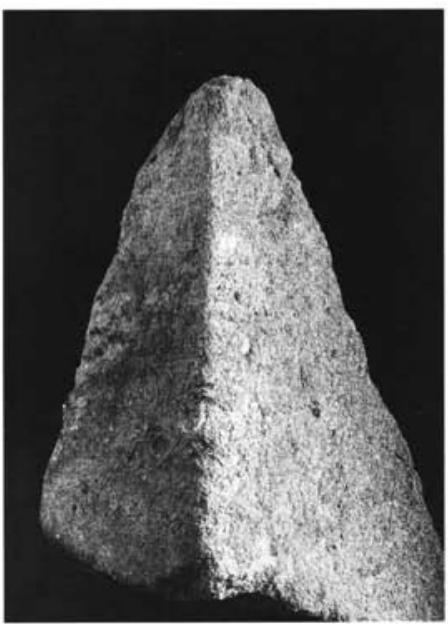

Lám. III. Estela piramidal: Inv² 1935/4.Vill./9. (Altura: $34 \mathrm{cms}$.; base: $22 \times 22 \mathrm{cms}$.).

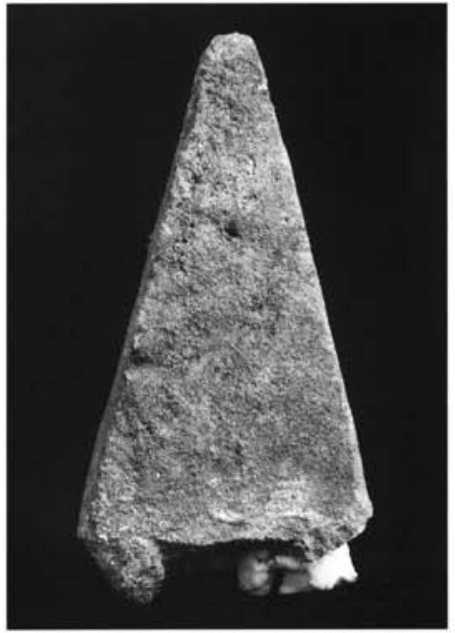

Lám. II. Estela piramidal: Inv $1935 / 4$.Vill./5. (Altura conservada: 21 cms.; base: $10,7 \times 10 \mathrm{cms}$.).

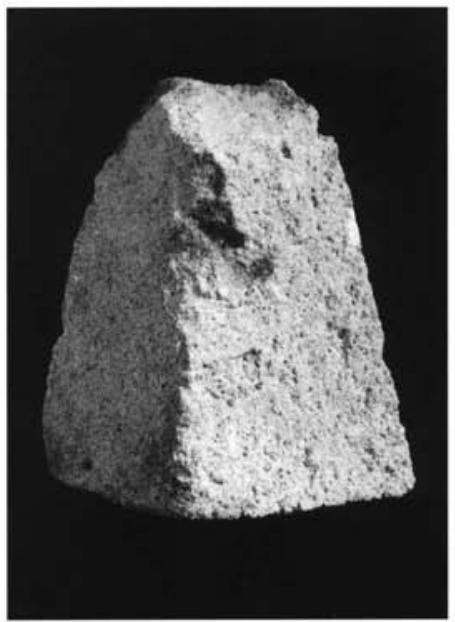

Lám. IV. Estela piramidal: Inv 1935/4.Vill./3. (Altura conservada: $13 \mathrm{cms}$; base: $10 \times 8 \mathrm{cms}$.). 

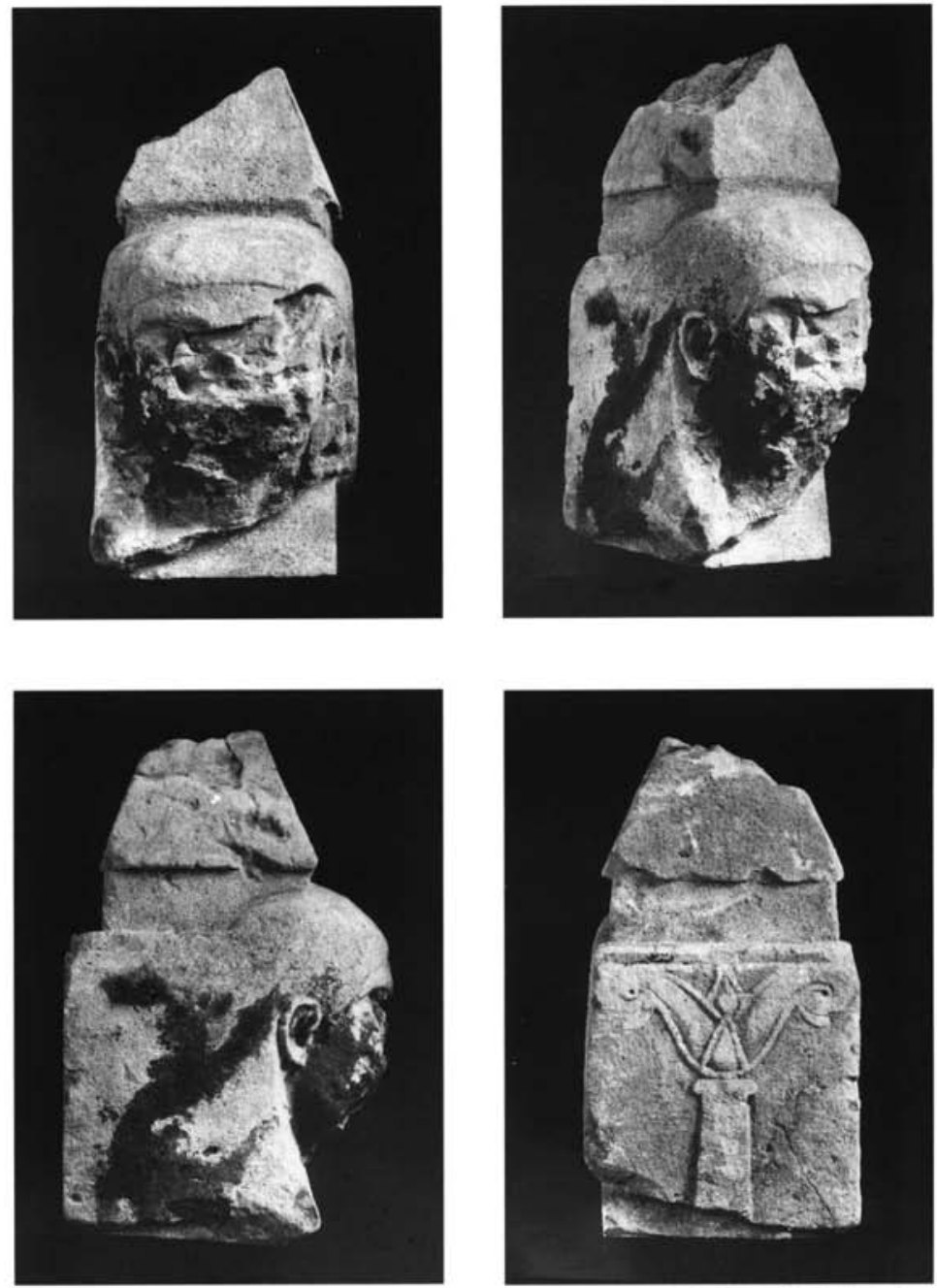

Lám. V. Estela con prótomo humano. Vistas frontal, lateral y posterior: Inv" 1935/4.Vill./521/3. (Altura conservada: $50 \mathrm{cms}$; base del pilar: $18 \times 23 \mathrm{cms}$.; base de la pirámide: $15.5 \times 18 \mathrm{cms}$.). 


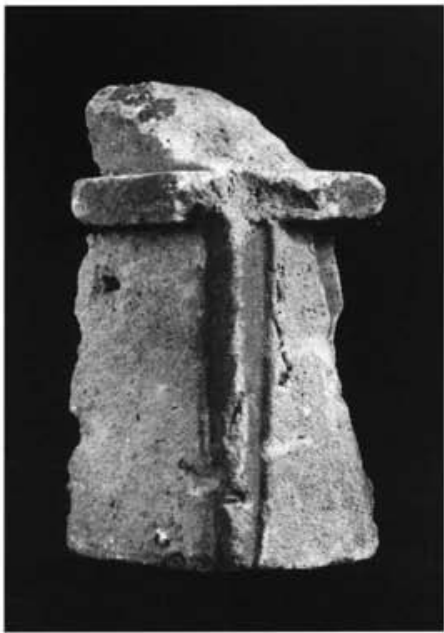

Lám. VI. Altar: Inve 1935/4.Vill./15. (Altura conservada: $28 \mathrm{cms}$.; base: $13 \times 13 \mathrm{cms}$.).

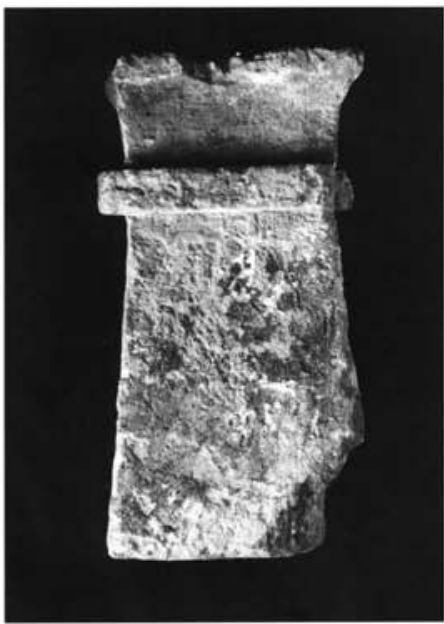

Lám. VIII. Altar: Inv 1935/4.Vill./20. (Altura: $65 \mathrm{cms}$; base: $30 \times 12.5 \mathrm{cms}$.).

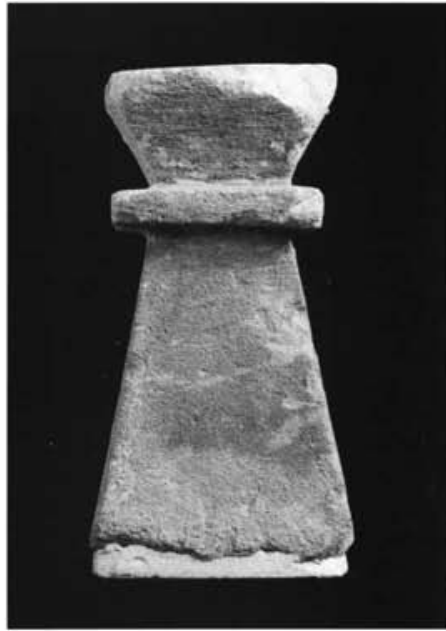

Lám. VII. Altar: Inve 1935/4.Vill./25. (Altura conservada: $35 \mathrm{cms}$.; base: $16,5 \times 12,5 \mathrm{cms}$.).

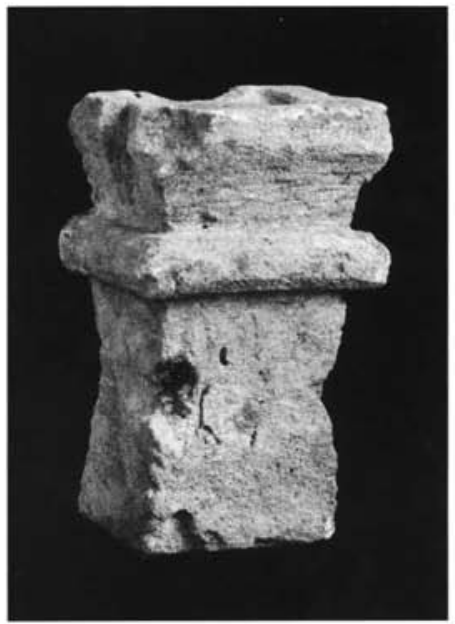

Lám. IX. Altar: Inve 1935/4.Vill./17. (Altura: 30,5 cms.; base: $14 \times 10$ cms.). 